\title{
Surgical Exposure of the Distal Fibula to Protect the Peroneus Brevis Muscle Vascular Pedicle
}

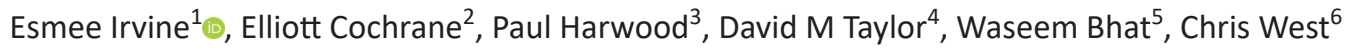

\begin{abstract}
Ankle fractures are a common presentation to orthopaedic surgeons, with the lateral malleolus involved in $86 \%$ of cases. A soft tissue injury can be a concomitant feature of these injuries as a result of the primary injury or following secondary wound breakdown. The peroneus brevis muscle flap provides a reliable and robust option to cover the distal third of the lower limb. With an understanding of the anatomy and cautious dissection during periosteal elevation, the perforating vessels supplying the peroneus brevis can be preserved ensuring that a valuable reconstructive option is available.

Keywords: Ankle fracture, Fibula fracture, Limb reconstruction, Muscle flap, Orthoplastics, Peroneus brevis.

Strategies in Trauma and Limb Reconstruction (2021): 10.5005/jp-journals-10080-1540
\end{abstract}

\section{INTRODUCTION}

Ankle fractures are a common presentation to orthopaedic surgeons, with an annual incidence of approximately 122-184/100,000 person years $(1: 800))^{1}$ The lateral malleolus is involved in $86 \%$ of ankle fractures; ${ }^{2}$ lateral malleolar fracture fixation for unstable or displaced ankle fractures (i.e. bimalleolar and trimalleolar) is typical with open reduction and internal fixation via a lateral approach.

A soft tissue injury can be a concomitant feature of these injuries, as a result of the primary injury or following secondary wound breakdown. Postoperatively, impaired wound healing is reported in between 3.2 and $9 \%$ of cases. ${ }^{3}$ Elderly patients and those with diabetes mellitus are at an increased risk of wound complications following fixation.

The British Association of Plastic, Reconstructive and Aesthetic Surgeons/British Orthopaedic Association Standards for the Management of Open Fractures state "All open fractures must be covered with a well-vascularised soft tissue within 72 hours of the injury to achieve an infection-free bony union". ${ }^{2}$ Owing to the limited local soft tissue availability around the ankle, open fractures in this area present a challenge to the surgeon. It is imperative to be aware of the relevant anatomy and potential reconstructive options at the time of performing debridement or skeletal fixation. Skin grafting defects are often not possible due to the limited underlying soft tissue. Free tissue transfer is a valuable option but is not suitable for all patients as it requires a significant physiological reserve. The peroneus brevis muscle flap provides a reliable and robust option to cover the distal third of the lower limb when free tissue transfer is not an option. We have used this technique successfully in four patients at our tertiary lower limb centre this year and would like to highlight both its practicality and important anatomical considerations for the orthopaedic surgeon.

\section{Peroneus Brevis Flap}

The peroneus brevis muscle lies on the lateral surface of the fibula, deep to the peroneus longus. It originates from the lower two-thirds of the fibula and inserts onto the fifth metatarsal
1,2,5,6 Department of Plastic and Reconstructive Surgery, Leeds General Infirmary, Leeds, United Kingdom

3,4 Department of Orthopaedic and Trauma Surgery, Leeds General Infirmary, Leeds, United Kingdom

Corresponding Author: Esmee Irvine, Department of Plastic and Reconstructive Surgery, Leeds General Infirmary, Leeds, United Kingdom, Phone: +07814912790, e-mail: esmee.irvine@doctors.org.uk How to cite this article: Irvine E, Cochrane E, Harwood P, et al. Surgical Exposure of the Distal Fibula to Protect the Peroneus Brevis Muscle Vascular Pedicle. Strategies Trauma Limb Reconstr 2021;16(3):176-178. Source of support: Nil

Conflict of interest: None

(Fig. 1A). According to the Mathes and Nahai classification, it is a type four muscle supplied via segmental perforating vessels arising from the peroneal artery and vein, passing posterior to the fibula; there is usually one large proximal and one large distal perforator. The peroneus brevis was first used as a distally based pedicled flap by Eren et al. ${ }^{4}$ (2001) allowing soft tissue coverage of the distal third of the lower leg including the proximal foot.

The flap is raised by marking the mid-lateral axis of the fibula and placing the incision $1 \mathrm{~cm}$ posterior to this line. The peroneus brevis is identified and raised off the fibula proximally by ligating the proximal perforator vessels, taking care to protect the motor branch of the superficial peroneal nerve until the distal perforators forming the pedicle are reached and preserved (Fig. 1B). The flap is transposed into the defect either by tunnelling the muscle or opening the skin. A split skin graft is then secured over the muscle (Fig. 1C).

Protection of the vascular pedicle is fundamental in ensuring the success of any pedicled flap. When undertaking fixation of fibular fractures, one should be mindful of the anatomy, particularly in high-risk patients, so that the pedicle can be protected should future reconstructive surgery be required. It may be prudent in cases that pose a high risk of wound breakdown to have a joint orthoplastic presence from the start of the procedure.

() The Author(s). 2021 Open Access This article is distributed under the terms of the Creative Commons Attribution-Non Commercial-share alike license (https://creativecommons.org/licenses/by-nc-sa/4.0/) which permits unrestricted distribution, and non-commercial reproduction in any medium, provided you give appropriate credit to the original author(s) and the source, provide a link to the Creative Commons license, and indicate if changes were made. If you remix, transform, or build upon the material, you must distribute your contributions under the same license as original. The Creative Commons Public Domain Dedication waiver (http://creativecommons.org/publicdomain/zero/1.0/) applies to the data made available in this article, unless otherwise stated. 

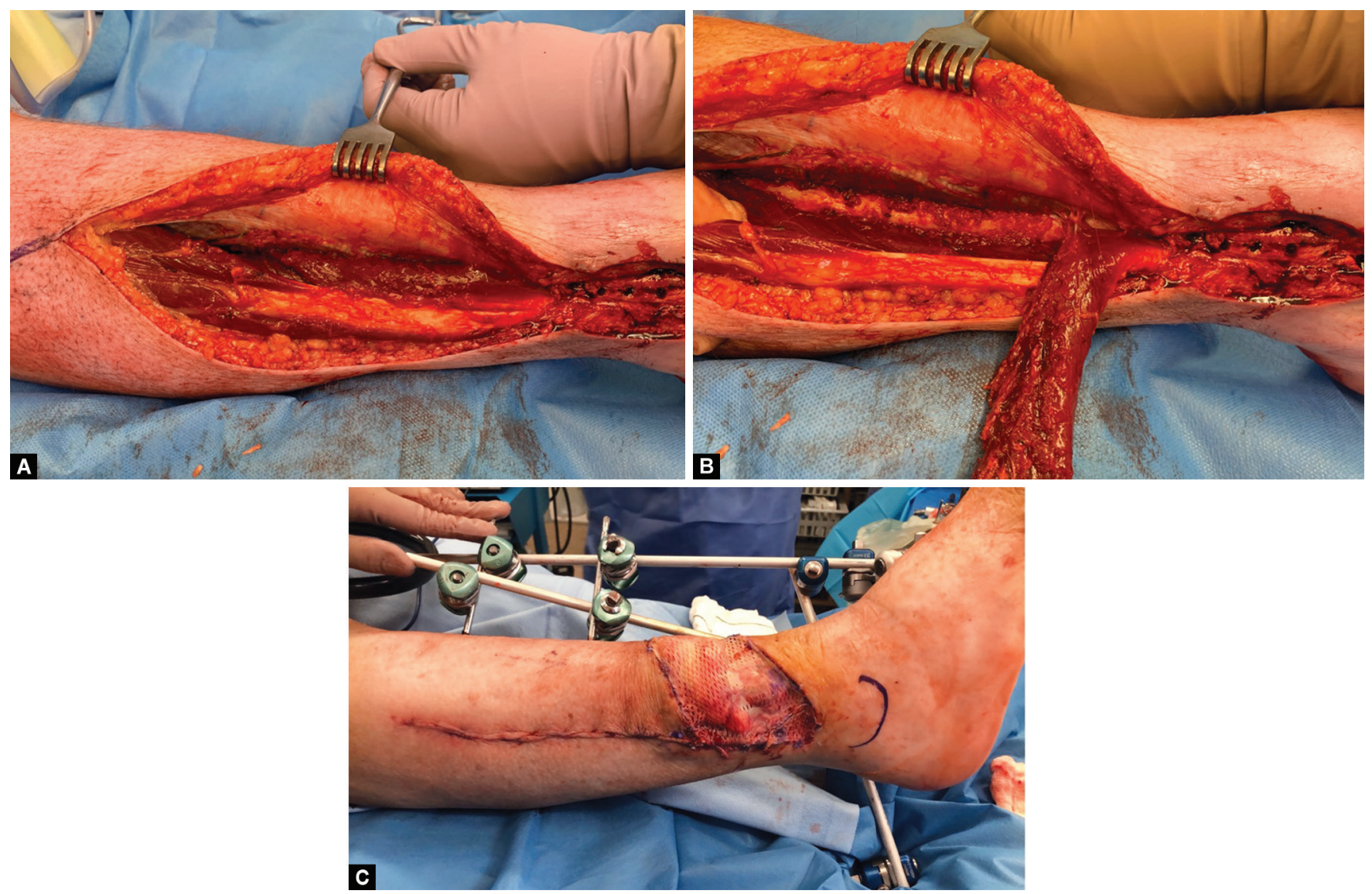

Figs 1 A to C: (A) Peroneus longus muscle with peroneus brevis lying deep and slightly anterior to it; (B) Peroneus brevis flap, raised proximally, supplied by distal perforators; (C) Distally based peroneus brevis flap used for soft tissue reconstruction in an elderly patient with an open ankle fracture who was only fit for spinal anaesthetic

The peroneal vessels run posteromedial to the fibula; segmental perforators arise from here passing around the posterior surface of the fibula to supply the muscle. Anatomical studies of the peroneus brevis muscle demonstrate the most distal perforator to be on average $4.25 \mathrm{~cm}$ (range $3-6 \mathrm{~cm}$ ) proximal to the lateral malleolus. ${ }^{5}$ Where possible, dissection of the musculature posterior to the fibula at this level should be avoided. If the bone must be exposed posteriorly, this should be undertaken carefully at a subperiosteal level starting laterally and working around the bone to avoid injury to the perforating vessels. However, excessive subperiosteal dissection may affect bone healing and increase the chance of heterotopic ossification.

Caution should be taken when delivering sharp bone ends or manipulating fracture fragments. Retraction levers, if used, should be placed carefully under direct vision onto the bone rather than through the muscle, as this can result in the pedicle being inadvertently divided or thrombosed due to excessive pressure or stretch. ${ }^{6}$ A summary of key points to protect the pedicle can be found in Table 1.

\section{Conclusion}

The distally based peroneus brevis muscle flap is a reliable option for managing soft tissue defects involving the distal third of the
Table 1: Key points to help the surgeon protect the peroneus brevis (PB) pedicle

1 Incision: Design an appropriate incision to provide good exposure of both the fibula and peroneus muscles.

2 Anatomical awareness: The blood supply to PB is segmental with the vessels running on the deep posterior surface of PB.

3 Avoid posterior dissection distally: The most distal perforator sits between 3 and $6 \mathrm{~cm}$ proximal to the lateral malleolus.

4 If posterior dissection is unavoidable, dissect posteriorly in a subperiosteal plane.

5 Retraction levers should be placed under direct vision onto the bone only.

6 Consider an orthoplastic presence in high-risk cases.

lower limb, including patients who are not fit for free tissue transfer. We have utilised this flap for use in acute trauma, fracture-related infections, exposed metalwork and chronic bone infection. It may also have a role in the reconstruction of chronic wounds and oncological defects. By cautious dissection during periosteal elevation, the perforating vessels supplying the peroneus brevis can be preserved ensuring that a valuable reconstructive option remains available. 


\section{OrCID}

Esmee Irvine 우 https://orcid.org/0000-0002-1606-8005

\section{References}

1. Mehta SS, Rees K, Cutler L, et al. Understanding risks and complications in the management of ankle fractures. Indian J Orthop 2014;48(5):445-452. DOI: 10.4103/0019-5413.139829.

2. Eccles $S$, Handley B, Khan U, et al., editos. Standards for the management of open fractures. Oxford, UK: Oxford University Press; 2020. Available from: https://oxfordmedicine.com/view/10.1093/ $\mathrm{med} / 9780198849360.001 .0001 / \mathrm{med}-9780198849360$ [Accessed September 10, 2021].
3. Simske NM, Audet MA, Kim CY, et al. Open ankle fractures are associated with complications and reoperations. OTA Int 2019:2(4):e042. DOI: 10.1097/OI9.0000000000000042.

4. Eren S, Ghofrani A, Reifenrath M. The distally pedicled peroneus brevis muscle flap: A new flap for the lower leg. Plast Reconstr Surg. 2001;107:1443-8.

5. Macera A, Carulli C, Sirleo L, et al. post-operative complications and reoperation rates following open reduction and internal fixation of ankle fracture. Joints 2018;6(2):110-115. DOI: 10.1055/ s-0038-1653949.

6. Yang YL, Lin TM, Lee SS, et al. The distally pedicled peroneus brevis muscle flap anatomic studies and clinical applications. J Foot Ankle Surg 2005;44(4):259-264. DOI: 10.1053/j.jfas.2005.04.013. PMID: 16012431. 